\title{
Escravidão: tema tabu para os museus de arte decorativa
}

\section{Resumo}

O ensino e a prática museal no campo da arte decorativa estiveram, durante muito tempo, aliados aos modos de pensar colonial e imperial, privilegiando concepções artísticas europeias, sacralizando objetos advindos das elites enriquecidas pelo trabalho escravo. Este texto apresenta reflexões de quase duas décadas de docência na área de arte decorativa para o curso de graduação em Museologia na Universidade Federal da Bahia (UFBA). O tema da escravidão de povos africanos tem sido tabu para os museus, ficando tais discussões reservadas àqueles específicos (etnográficos e históricos), omitindo-se, dessa forma, que a formação econômica dos países colonizados e suas metrópoles se deu através dessa força de trabalho. $\mathrm{O}$ caminho metodológico para enfrentar esse tabu tem sido o de descolonizar o olhar em arte decorativa, o que implica suscitar uma tomada de posição crítica frente aos acervos hegemonicamente estabelecidos, ainda ancorados na chegada, conquista e estabelecimento dos europeus nas Américas como marco fundante de processos civilizatórios. O termo colonial não se aplica exclusivamente aos processos de governança, mas ao campo epistemológico, à manutenção do conhecimento eurocentrado. A docência nessa área é desafiadora, pois está atrelada aos acervos, resultantes da permanência de padrões e gostos coloniais-eurocentrados, não somente no campo artístico, mas também no campo das mentalidades.

Palavras-chave: Escravidão. Museus de arte decorativa. Descolonização do olhar.

\author{
Joseania Miranda Freitas \\ Doutora em Educação pela \\ Universidade Federal da Bahia - \\ UFBA. Professora da \\ Universidade Federal da Bahia - \\ UFBA. \\ Brasil \\ joseaniafreitas@yahoo.com.br
}

\section{Para citar este artigo:}

FREITAS, Joseania Miranda. Escravidão: tema tabu para os museus de arte decorativa. Revista PerCursos, Florianópolis, v. 20, n.44, p. 56 - 76, set./dez. 2019.

\section{DOI: $10.5965 / 1984724620442019056$}

http://dx.doi.org/10.5965/1984724620442019056 


\title{
Slavery: taboo theme for decorative art museums
}

\begin{abstract}
The teaching and practice of Museology in the field of decorative art were, for a long time, tied to colonial and imperial ways of thinking that privileges European artistic conceptions, sacralizing objects from the elites enriched by the slave labor. This article presents reflections built over more than two decades of teaching in decorative art for undergraduate students of Museology course at the Universidade Federal da Bahia (UFBA). The subject of slavery of Africans has been a taboo for museums, a topic solely concerned to ethnographic and historical museums, thus omitting the role of slaves in economic formation of the colonized countries and their metropolises. A methodological path to face this taboo is to decolonize the teaching of decorative art, which implies to adopt a critical stance against the hegemonically established collections still anchored in the idea of Europeans as a founding landmark of civilizing processes in America. The term colonial does not apply exclusively to governance processes, but it's also related to the epistemological field, to the maintenance of Eurocentric knowledge. Teaching in this area is a challenging issue, since this sort of art is linked to the collections resulting from the permanence of Eurocentric colonial patterns and tastes in the artistic field as well as the field of mentalities.
\end{abstract}

Keywords: Slavery. Decorative art museums. Decolonial thoughts. 
A partir de 1492 e pelo viés do comércio triangular, o Atlântico tornou-se um verdadeiro aglomerado, que agregou a África, as Américas, o Caribe e a Europa em torno de uma intricada economia. [...] Os povos de origem africana estavam no centro dessas novas dinâmicas que implicavam incessantes idas e vindas de uma margem a outra do mesmo oceano, dos portos negreiros da África Ocidental e Central aos da América e da Europa. [...] um processo inédito de crioulização foi desencadeado e resultou num intenso tráfego de religiões, línguas, tecnologias e culturas. [...] (MBEMBE, 2018, p. 34-35).

As palavras do camaronês Achille Mbembe, em Crítica da razão negra, evidenciam importantes dados, geralmente silenciados nos museus, principalmente os de arte decorativa, destinados à exibição de objetos utilitários que, por suas características artísticas, são também considerados obras de arte. Nos países que passaram por processos de colonização, metrópoles europeias e suas colônias, essa categoria de museus, correntemente, falha em estabelecer relações explícitas de seus acervos com a necessária presença de povos africanos escravizados na constituição do status social das elites nela representadas. Ao expor as suas coleções, os museus tendem a não revelar a base da riqueza das elites que nelas são destacadas; apresentam os vestígios nobiliárquicos sem referência completa à historicidade dos objetos. Além do silêncio sobre a presença dos povos africanos escravizados como força motriz do sistema econômico colonial, omitem informações preciosas sobre os processos de produção, incluindo a extração e tratamento das matérias-primas para a produção, o comércio e a circulação dos objetos até que estes cheguem ao processo final de exibição nos museus.

A lógica expositiva desses museus constantemente mantém a obviedade oferecida pelos objetos, sem ultrapassar a descrição física e funções; costuma repetir os ambientes suntuosos das casas senhoriais, nas metrópoles e nas colônias, privando o público de receber informações mais amplas relativas ao mobiliário, louças, prataria, ourivesaria e demais adornos, como tapetes, indumentárias, vidros e cristais entre tantos 
outros objetos que marcaram as hierarquias coloniais. Essa lógica expositiva é, geralmente, festejada e fetichizada pelas elites, outrora consumidoras e/ou apreciadoras dos objetos de exceção que foram musealizados, por suas características materiais, marcadamente intrínsecas de suntuosidade, raridade, antiguidade, sem apresentar expograficamente articulações com o campo extrínseco.

No Brasil, as práticas museais, notadamente no campo da arte decorativa, contribuíram para a cristalização de concepções de museus como lugares para a celebração das hegemonias políticas, econômicas e sociais, aliadas aos modos de pensar colonial e imperial que, além de invisibilizar e silenciar povos indígenas e africanos, privilegiou concepções artísticas europeias (principalmente o barroco, o rococó e o neoclássico), sacralizando objetos de exceção, como se o uso dos objetos decorativos estivesse restrito às nobrezas europeias nas metrópoles e nas suas representações coloniais. Tal postura levou as instituições e acervos a serem vistos como elitistas e contemplativos.

A opção por modelos expográficos que fragmentam as informações consolida o formato de história única, hegemônica, branca e falocêntrica, sedimentando mentalidades coloniais. Mentalidades que persistem e sustentam as relações econômicas atuais, como chamam atenção as palavras de Aníbal Quijano ${ }^{1}$ em abordagem acerca da colonialidade, ou seja, sobre as permanências do colonialismo como eixo de sustentação dos padrões de poder, independentemente da dominação colonial:

Um dos eixos fundamentais desse padrão de poder é a classificação social da população mundial sobre a ideia de raça, uma construção mental que expressa a experiência básica da dominação colonial e que desde então permeia as dimensões mais importantes do poder mundial, incluindo sua racionalidade específica, o eurocentrismo. Este eixo tem, portanto, origem e caráter colonial, mas provou ser mais durador e estável que o colonialismo em cuja matriz foi estabelecida. Implica, como consequência, um elemento de colonialidade no padrão de poder hoje globalmente hegemônico. [...]. (QUIJANO, 2005, p. 117).

\footnotetext{
${ }^{1}$ Texto escrito em 1992, aqui trabalhamos a edição atualizada em 2005.
} 
Uma das possibilidades de burlar as tramas hegemônicas nas quais os museus de arte decorativa estão entrelaçados seria a construção de narrativas expográficas que explicitem os modos de enfrentamento da permanente colonialidade e possam romper “[...] com a história única, sustentada pelas metanarrativas que legitimaram as ideologias do processo de colonização, [...] a partir das diferenças raciais hierarquizadas como justificativa para o 'processo civilizatório' [...]" - como salienta Rosane Pezzodipane (2013, p. 88).

Silenciar é também uma forma de negar, faz parte do jogo de poder para manutenção de registros históricos de forma linear e unilateral. A fetichização dos objetos de arte decorativa, em muitos casos, se estendeu ao fazer museal, em detrimento do uso da historicidade como elemento comunicacional. Felizmente, os estudos relativos à cultura material avançaram, incluindo possibilidades de "novas" interpretações para "velhos" objetos, principalmente através do movimento da Nova História e da Nova Museologia, que puseram em evidência a importância de elementos da vida privada (em cuja seara a maior parte dos objetos de arte decorativa se encontra) para elucidar tramas sociais, com seus marcadores de hierarquias e lugares políticos, as relações de poder, de gênero, de geração e das mentalidades. No entanto, esses avanços teóricos e empíricos da história e da museologia não ecoaram de forma mais contundente com relação à discussão e exposição da historicidade dos objetos, no tocante às produções culturais elaboradas no período da escravidão. As "[...] manchas de sangue [...] visíveis por toda a superfície da modernidade" - como pontua Mbembe (2018, p. 63) ao analisar a escrita fragmentada da história de negras e negros - são invisibilizadas nas sociedades europeias e americanas, enriquecidas e constituídas durante os processos coloniais.

A dificuldade no enfrentamento das tramas hegemônicas não é só dos museus de arte decorativa, podendo ser observada também com relação ao pensamento social brasileiro, como esclarece a filósofa Suely Carneiro (2011, p. 16) quando afirma que há “[...] postergação do reconhecimento da persistência de práticas discriminatórias em nossa sociedade". Ou, ainda, seria possível articular essa dificuldade à persistência do “racismo internalizado" que, na análise da estudiosa afro-estadunidense bell hooks 
$(2019)^{2}$, relaciona-se ao uso das "lentes da supremacia branca"3 para produção de imagens midiáticas. Mesmo sem citar diretamente os museus, essas reflexões sobre imagens podem ser articuladas a essas instituições:

Ao abrir uma revista ou um livro, ligar a TV, assistir a um filme ou olhar fotografias em espaços públicos, é muito provável que vejamos imagens de pessoas negras que reforçam e reinstituem a supremacia branca. Essas imagens podem ser construídas por pessoas brancas que não se despiram do racismo, ou por pessoas não brancas ou negras que vejam o mundo pelas lentes da supremacia branca - o racismo internalizado. (HOOKS, 2019, p. 32).

As legitimadas narrativas expositivas de acervos ancorados em bases eurocêntricas e racistas ${ }^{4}$ precisam ser postas em discussão, de forma a evidenciar a presença dos povos africanos em toda a constituição do país, uma vez que o trabalho escravizado sustentou não somente as lavouras - como ingenuamente se costuma cristalizar a participação das mãos africanas -, mas serviu de esteio para a diversificada produção de cultura material e imaterial do país, como elucida Emanoel Araújo, diretorcurador do Museu Afro Brasil, em São Paulo:

A negação do passado científico e tecnológico dos povos africanos e a exacerbação do seu caráter lúdico são algumas das principais façanhas do eurocentrismo, abalando fortemente, ainda hoje, a autoestima da população africana e da diáspora. [...] A produção de instrumentos de trabalho, técnicas de edificações e, até mesmo, de objetos artísticos constitui um legado imprescindível para compreender a história do desenvolvimento tecnológico no Brasil. Por muito tempo, interessou aos que escreviam a nossa História reforçar um passado sofrido e 'coisificação', com intuito de cristalizar imagens de uma suposta subalternidade. (ARAÚJO, 2013, p. 33-34).

\footnotetext{
${ }^{2}$ A primeira edição data de 1992.

3 Ainda que no caso brasileiro e demais ex-colônias americanas o conceito de "supremacia branca" seja utilizado por indivíduos que nos Estados Unidos não seriam considerados brancos, mas latinos, mestiços, etc. - tal uso tem levado à construção de imaginários exclusivos: o "socialmente branco", "religioso cristão" e "heteronormativo" - que discrimina quem não se encaixa nesses padrões.

${ }^{4}$ Os principais museus e coleções formados no século XIX tiveram como base as ideias raciais e racistas, desenvolvidas na Europa e espalhadas nas colônias.
} 
A literatura produzida por mulheres negras brasileiras tem contribuído para novas formas de registros históricos, que respondem ao apelo de bell hooks de que é preciso ousar para produzir diferentes modos de quebrar a perspectiva colonizadora: “Desafiados a repensar, artistas e intelectuais negros insurgentes buscam novas formas de escrever e falar sobre raça e representação, trabalhando para transformar a imagem" (HOOKS, 2019, p. 33). Neste texto, destacam-se as contribuições da escritora Eliana Alves Cruz (2018), que ao construir narrativas de memórias autobiográficas terminou por biografar várias gerações afro-brasileiras, registrando vozes abafadas de mulheres negras que cuidaram da manutenção de casas senhoriais e foram responsáveis pela sustentação silenciosa da vida privada nas cidades e no campo. Eliana abre o seu livro, Água de Barrela ${ }^{5}$, com a seguinte nota:

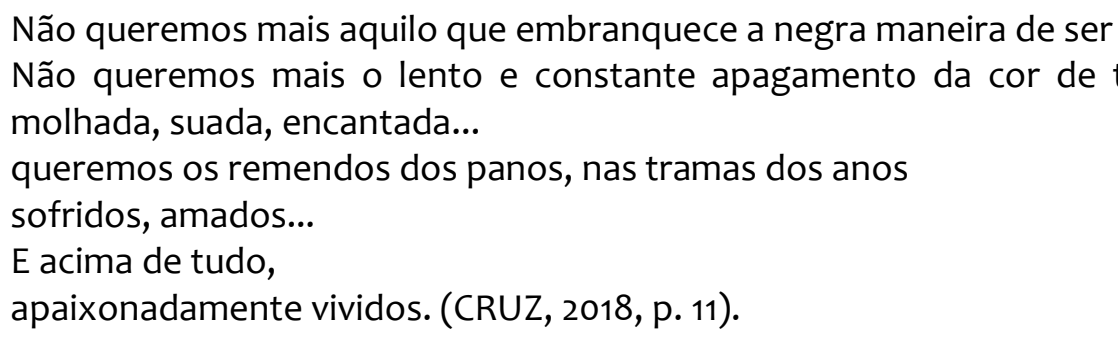

A sua escrita mescla, de forma magistral, história e literatura, partindo do solo fértil do Recôncavo Baiano para recuperar memórias familiares, principalmente de mulheres, zeladoras dos objetos das famílias dos senhores de engenho, que atualmente habitam os museus de arte decorativa. Há em toda a trama uma riqueza de elementos do legado imaterial da gente africana e sua descendência, assim relatado pela autora: “É impossível não pensar no conceito que diz que a matéria se acaba, mas o que é do espírito se eterniza" (CRUZ, 2018, p. 305). No campo material a trama apresenta, como ponto de partida para as análises, somente três objetos que se caracterizam como arte sacra e arte decorativa e uma carta: o "Fio de contas de Xangô que pertenceu a Martha” e uma "Boneca de porcelana de Nunu, xícara e pires de porcelana de Celina. Duas das únicas peças do enxoval de casamento que não foram quebradas por Nunu."

\footnotetext{
${ }^{5}$ Prêmio concurso de romances da Fundação Palmares e Prêmio Thomas Skidmore, em 2018, no mesmo ano da publicação, o segundo prêmio garante a publicação em língua inglesa.
} 
Datada de 27 de setembro de 1993, a "Carta de Mary Santos Silva. Descendente dos Tostas que escreveu para Celina, avó da autora" (p. 313-314) - missiva que levou a autora à busca de outras pistas e fontes que se somaram aos relatos da sua tia-avó Anolina, a tia Nunu. Com apenas esses dados materiais, Cruz partiu para o ponto mais sensível da narrativa histórico-literária: registrar os depoimentos da tia, recolhidos por meio de um exercício de sensibilidade, mergulhando no universo de uma pessoa com esquizofrenia, de forma a encontrar, no espaço temporal em que a mesma vivia, os laços que compõem as narrativas: "Eu anotava tudo o que podia e partia para pesquisar. Todas as informações conferiam com registros históricos, com a descrição dos locais [...]" (CRUZ, 2018, p. 309).

Registros dessa natureza, que entrelaçam histórias de vidas, precisam ser evidenciados nos museus de arte decorativa para o enriquecimento das tramas documentais e expográficas, pois suscitam a produção de pesquisas e ações educativas, abrindo horizontes para a compreensão mais ampla dos acervos que derivaram do cenário da Bahia colonial, com seu Recôncavo rural e sua capital, Salvador, repletos de casas senhoriais de onde saíram os principais acervos dos museus de arte decorativa. Vale atentar para registro de Wanderley Pinho ${ }^{6}$ que capta a pujança de uma era:

Não eram muito raros os casos de senhores de engenho possuírem, compostas e completas, duas ou três residências, com todos os atavios. Vindo-Ihes um novo engenho, por herança ou compra, estava no brio do adquirente conservar a 'casa montada', ou ainda que a não habitasse, e escassamente a visitasse. (PINHO, 1982, p. 442).

Nas vitrines dos museus de arte decorativa são destacados objetos de condes, viscondes, barões e de outros títulos nobiliárquicos, além dos chamados fidalgos “[...] ('filhos d'algo') - aristocracia militar detentora da autoridade régia” (ALENCASTRO, 2000, p. 15) - sem relacioná-los à história desses personagens, como relata o historiador Walter Fraga, com base em crônicas de João da Silva Campos:

\footnotetext{
${ }^{6}$ Nesta obra, publicada originalmente em 1946, são apresentadas diversas ilustrações de objetos que atualmente se encontram nos museus de arte decorativa de Salvador.
} 
De histórias de senhores de engenho cruéis e malvados, a tradição oral dos habitantes do Recôncavo Baiano é farta. Não faltam histórias de infelizes escravos que foram metidos em fornalhas ardentes, atirados em tachos de mel fervente, enterrados vivos, mortos no tronco ou a chicote. Mas a tradição oral, em revide, não deixa de mencionar os fins trágicos que levaram esses mesmos senhores, decaídos na pobreza ou ceifados pela reação silenciosa ou explosiva dos próprios cativos. (FRAGA, 2014, p. 57).

Há na trajetória histórica dos engenhos momentos de apogeu e decadência do poder hegemônico, assim como ações contra hegemônicas empreendidas pelas pessoas em situação de escravidão, que revidavam de diversificadas formas. No entanto, a opção dos museus de arte decorativa, salvo em pontuais exposições temporárias, tem sido a utilização de narrativas mais estáticas, centradas nos proprietários dos objetos, cristalizados em seus períodos áureos, quando tais objetos faziam parte de um cotidiano que foi desmontado, não exclusivamente pela abolição, como costuma ser cristalizado, muitas vezes, nas memórias de representantes das velhas aristocracias rurais da cana-deaçúcar, como exemplifica a literatura de Cruz no registro de um rápido e importante relato de uma senhora ao deparar-se com uma peça da família em um museu histórico, repleto de objetos de arte decorativa:

[...] Foram ao Museu Histórico Nacional, onde acontecia uma exposição e ela identificou uma bacia de ouro que pertencera a sua família. Teve apenas uma frase diante do objeto, mas que valeu por um discurso:

- A princesa Isabel... Aquela vaca! (CRUZ, 2018, p. 303).

A decadência dos engenhos se deu por razões mais complexas, que envolviam modernização do velho sistema de moagem e produção do açúcar, agravadas por dívidas e falências que acometeram os engenhos do Nordeste do país, como notou Pinho:

[...] a crise das lenhas continuava e se agravava para os engenhos de beira-mar. [...]

[...] Numerosos sobrados vieram a arruinar-se abrigando apenas, por longos anos, um escravo velho de confiança, para guardar e vigiar o que ia dia a dia perecendo [...]. (PINHO, 1982, p. 225 e 442). 
Outro contundente silêncio ronda essa categoria de objetos. Trata-se daquele relativo às tramas histórico-raciais que permeiam os objetos de arte decorativa pertencentes às ordens religiosas, proprietárias de terras e engenhos, e também escravistas, como analisa Fraga (2014) com base nas pesquisas de Stuart B. Schwartz: “[...] Os carmelitas destacavam-se como grandes proprietários de escravos, ao todo 255 cativos. [...]". O autor segue enumerando as propriedades, acrescentando que os carmelitas “[...] não eram os únicos religiosos a se envolver em empreendimentos agrícolas. Beneditinos e jesuítas (estes até 1759) foram também grandes proprietários de terras e engenhos no Recôncavo" (FRAGA, 2014, p. 66-67).

Esses acervos nobiliárquicos nos museus de arte decorativa de Salvador destacam o protagonismo de seus proprietários, mantendo a lógica normativa, apresentando homens e seus títulos, mesmo no caso daqueles objetos que não costumam ser associados ao campo masculino, a exemplo das louças de uso doméstico. Nas descrições das etiquetas e catálogos não aparecem questionamentos a esse respeito. Apresentam as louças europeias brasonadas ou monogramadas sem estabelecer relação com a sua produção; são expostas ao público sem menção às ações de espionagem da produção da porcelana chinesa, sem articulá-las ao longo processo de acertos e erros das manufaturas de louça na Europa até o domínio técnico da produção da pasta da porcelana conforme a tradição chinesa. Sem informações sobre as importações e encomendas e, muito menos, sobre as mãos femininas responsáveis pelo uso e cuidado cotidiano dessas finas peças, bem como sobre os sujeitos trabalhadores, quer da produção, quer da manutenção das casas. Os senhores barões, condes, viscondes etc. ganham evidência silenciando as mulheres, mesmo as brancas. Em relação às demais categorias de objetos, mobiliário e metalurgia decorativa, o modelo - sem privilegiar as relações pessoais - se repete.

Rosana Nascimento, ao estudar uma peça de porcelana de exportação do acervo do Museu de Arte da Bahia já alertava para a importância do estudo da historicidade dos objetos, pois o que tem sido destacado:

[...] reforça as aparências, dando ênfase aos valores estéticos, exóticos, antiguidades, raridades, etc. do acervo, como também, escamoteando as 
relações do homem com o seu meio, priorizando uma abordagem puramente factual, onde os objetos são expostos obedecendo uma fragmentação e uma linearidade histórica. (NASCIMENTO, 1993, p. 1).

As práticas museais que reforçam "as aparências" encontram nas etiquetas expositivas um lugar perfeito para a explicitação dos elementos hegemônicos e homogêneos, silenciando as dinâmicas da vida que os objetos carregam. Para além da redução textual exigida nas etiquetas, faltam outros materiais expográficos que complementem as informações, que permitam explicitar a riqueza das trajetórias de vida dos objetos, dos sujeitos implicados, assim como as trajetórias institucionais.

\section{Reflexões sobre a descolonização do olhar em arte decorativa}

Descolonizar o olhar implica a realização de práticas museais que visam enriquecer as possibilidades de comunicação dos acervos, de forma a agregar novos e velhos conhecimentos, explicitando as contradições, as disputas, a exploração ambiental e humana, as relações de poder que levaram à constituição dos mesmos. Os objetos de arte decorativa oriundos, principalmente, do mundo doméstico-privado, carregam suas marcas de objetos utilitários, estão repletos do sensorial, do toque constante das pessoas de épocas e classes sociais diferentes. Possuem intensas marcas de vida, mas ao chegarem aos museus, geralmente, perdem parte dessa força comunicacional, que poderia levar à "[...] abstração e sensibilidade essenciais à compreensão dos fatos sociais [...]" - salientadas pelo historiador francês Daniel Roche (2000, p. 13).

Nessa perspectiva, vale lembrar a experiência do artista visual afro-estadunidense Fred Wilson, que realizou significativas instalações nas "celebrações e impugnações"7 do V Centenário da América, no Museu Histórico de Baltimore, nos Estados Unidos, utilizando acervo institucional de arte decorativa. A instalação Metal Work (Trabalho em Metais) reuniu no mesmo cenário expográfico a prata e o ferro, forçando o entrelaçamento de histórias na exibição de um serviço de mesa em prata que, à distância, se via como "[...] uma formidável coleção de prataria. Nos aproximamos curiosos, como

\footnotetext{
${ }^{7}$ Expressão de Walter Mignolo (2010).
} 
nos aproximamos de todo objeto exposto no museu. Ao chegar, vemos que no meio da vitrine foram colocadas as algemas que eram usadas para aprisionar os escravos" (MIGNOLO, 2010, p. 13) ${ }^{8}$. Dois metais que forjaram a vida colonial nas Américas e nas metrópoles europeias: a prata, trabalhada em batidos, repuxados, gravados e cinzelados $^{9}$, com seu brilho acentuado foi colocada ao lado do opaco ferro destinado ao castigo; ambos testemunhas da exploração do trabalho escravo. As algemas explicitavam a presença de seres humanos escravizados - destacando não as ações construtivas de trabalho, mas o castigo, como geralmente fica sintetizado para os museus a presença da mão de obra africana. A instalação foi também uma denúncia das formas de tratar as memórias e trajetórias dos seres humanos escravizados nos museus.

A mão de obra para o trabalho com a prata, no Brasil colonial, envolvia escravizados, alforriados e libertos, mas durante muito tempo foi invisibilizada e silenciada. Mesmo que as mãos, de mulheres e homens, não estivessem na produção material da prataria, estavam no cotidiano do preparo das mesas a serem servidas, na limpeza e manutenção da prataria e de toda a casa. No entanto, essas informações não se fazem presentes nas exposições, mesmo contando com acervo que, direta e indiretamente, está implicado com as tramas coloniais escravistas. Predomina o silêncio sobre a presença de homens e mulheres subjugados ao perverso sistema escravista.

Os viajantes alemães Von Spix e Von Martius (1976, p. 65) destacam em suas anotações que "[...] os artesãos trabalham com seus próprios escravos pretos, que sob severa disciplina dos seus senhores aprendem, além da habilidade e aptidão no ofício, também a virtude da ordem civil”. No entanto, foram estabelecidas leis proibitivas à utilização da mão de obra escravizada, dentre as quais se destaca o Alvará de 1621. A estudiosa da prataria Mercedes Rosa (1980) chama atenção para o fato de que, graças ao descumprimento às leis foi possível a produção da prataria dos balangandans, originalmente baiana:

\footnotetext{
${ }^{8}$ Tradução nossa do original: “[... ] una formidable colección de platería. Nos acercamos curiosos, como nos acercamos a todo objeto expuesto en el museo. Al llegar, vemos que en el medio de la vitrina han sido colocadas las esposas que se usaban para sujetar a los esclavos."

9 Técnicas decorativas empregadas nos metais, para produção de efeitos de alto e baixo relevos.
} 
E já deviam ser bons, pois os livros dos viajantes, elementos preciosos para informações desse tipo, informavam que a ourivesaria colonial estava entregue, em grande parte, a 'pretos e mulatos'. [...] pois grande parte deles apresentavam a agravante de serem escravos. Mas a inquietação já vinha de muito antes, como comprova o Alvará de 20 de outubro de 1621 , que os proibia terminantemente de exercer essa arte. $O$ que parece evidente é que essas legislações nunca foram integralmente cumpridas. Antes assim, pois foi precisamente à cultura dos que foram proibidos de exercer essa nobre arte, que ficamos devendo os inconfundíveis e únicos exemplares da prata brasileira, com originalíssimas características, e que são os movimentados, misteriosos e mágicos balangandans. (ROSA, 1980, p. 3).

Prosseguindo com a análise de Rosa sobre o contexto da produção da prata e do ouro, constata-se que a produção nacional ameaçava a produção da metrópole, provocando:

[...] prejuízo do erário real, e de que o contrabando desviava o ouro de Minas Gerais, atribuindo-se isso a descontrolada proliferação de oficias da Colônia surgiu em 30 de julho de 1766 a Carta Régia determinando fossem incorporados aos Regimentos Militares, os oficiais, aprendizes do ofício do ouro e da prata, 'solteiros ou pardos forros', que se fechassem as lojas, se sequestrassem os instrumentos e se demolissem as forjas, que os mestres se comprometessem, por escrito, a não reabrir as oficinas e que os aprendizes ou artífices escravos regressassem ao domínio dos seus senhores. Como terrível consequência, foram demolidas 158 oficinas. Esta violenta proibição vigorou até 11 de Agosto de 1815. (ROSA, 1980, p.3).

Relativamente à mão de obra escravizada utilizada no trabalho da produção de metais, Lysie Reis (2013) aponta que essa participação contou com homens que já dominavam as técnicas da metalurgia:

Havia apenas uma brecha: o ofício de ferreiro admitia negros africanos e crioulos [...] O ferreiro, por ser na África um indivíduo de reconhecida qualificação, não necessitava de iniciação no ofício. Já chegava qualificado. Se lhe era permitida inserção, certamente lhe reconheciam atributos e mestria no desempenho do ofício. A modificação na lei nada mais era do que uma confirmação da sua atuação costumeira e, para além desta, havia inúmeras que, independentes de serem anuídas 
legalmente, inseriam os homens 'de cor', escravos, forros ou livres nos ofícios mecânicos. Se essa inserção já é conhecida, pouco se sabe sobre seus meandros e especificidades, não só na Bahia, como no Brasil. (REIS, 2013, p. 72).

As habilidades não se restringiam ao campo da metalurgia, mas aos demais campos produtivos da época. Nepomuceno faz menção ao aumento numérico de artífices nas cidades brasileiras, incremento devido, principalmente, à presença de alforriados:

[...] a partir da metade do século XVIII, um crescente número de alforriados gerou, nas cidades brasileiras, uma ampla camada de artífices, como carpinteiros, marceneiros, entalhadores, mestres de obra, ferreiros, ourives, alfaiates, barbeiros, dentistas, mineradores, músicos etc. [...]. (NEPOMUCENO, 2006, p. 36).

Incorporar as tramas das dimensões da materialidade e imaterialidade dos objetos articulados às dinâmicas da vida social tem sido um dos grandes desafios dos museus de arte decorativa, ainda que se possa elencar pontuais, raras e excelentes, experiências com a realização de trabalhos críticos e criativos com os acervos. No Brasil, e mais especificamente na Bahia, os acervos de arte decorativa são resultantes das permanências de padrões e gostos coloniais eurocentrados, não somente no campo artístico, mas também no campo das mentalidades. O termo colonial não se aplica exclusivamente aos processos da governança política portuguesa, mas ao campo epistemológico, à permanência do conhecimento eurocentrado. Determinados aspectos do colonialismo se perpetuaram como "[...] colonialidade do poder e do saber", como lembra Aníbal Quijano (2010) - essa colonialidade é, geralmente, restritiva, principalmente no caso das informações disponibilizadas nas exposições dos museus, que silenciam e invisibilizam outras matrizes decorativas.

Tais reflexões se alinham às ideias discutidas por Boaventura de Sousa Santos e Maria Paula Meneses na Introdução da obra “Epistemologias do Sul”: 
[...] o colonialismo, para além de todas as denominações por que é conhecido, foi também uma dominação epistemológica, uma relação extremamente desigual de saber-poder que conduziu à supressão de muitas formas de saber próprias dos povos e/ou nações colonizados. (SANTOS; MENESES, 2010, p. 19)

O silêncio sobre a historicidade dos acervos se mostra um desafio constante para as equipes de profissionais dos museus de arte decorativa. O silêncio sobre os sujeitos relacionados aos objetos tem sido recorrente nos museus, que optaram por “[...] apresentar ao máximo de pessoas o maior número de elementos criadores de prazer estético [...]" (MOLES, 1981, p. 75), em lugar de trazer elementos reflexivos sobre a historicidade dos objetos, que terminam por serem apresentados isolados de sua cadeia de produção, utilização e musealização. A prática expositiva dos museus ainda mantém atual a crítica de Abraham A. Moles, publicada originalmente no início dos anos setenta (1972), que "[...] nos afasta do universo cotidiano do objeto, que é o que nos interessa [...]" (MOLES, 1981, p. 2).

Tal postura, distanciada da historicidade, salienta o que o francês George DidiHuberman (2013, p. 67), historiador da arte, chama de "tirania do visível”, quando discute sobre a acumulação de visibilidade na história da arte: “A história da arte não conseguirá compreender a eficácia visual das imagens enquanto continuar entregue à tirania do visível [...]". Apresentar objetos que provoquem o "prazer estético", na dinâmica do “visível” não elimina as possibilidades de inserção de componentes críticos, analíticos, que os contextualizem historicamente. Ao optar por privilegiar a visibilidade dos objetos, os museus silenciam os seres humanos, emudecendo-os junto aos objetos. São ainda escassas as referências sobre os sujeitos produtores, seus materiais e técnicas construtivas; os modos de uso são pouco explorados.

\section{Considerações finais}

Ao tratar da escravidão como um tema tabu para os museus de arte decorativa, afinamos com o desafio proposto por Hooks (2019, p. 36) "[...] de falar sobre aquilo que 
não foi falado", visando suscitar novas abordagens museais e museológicas que possam interrogar, como sugere a autora, “[...] criticamente as velhas narrativas, sugerindo formas alternativas de contemplar a negritude, a subjetividade das pessoas negras e, por necessidade, a branquitude." Alternativas inclusivas e transgressoras, no sentido de tocar num dos pontos mais importantes para a construção da nação, que se ergueu graças à força de trabalho dos corpos de africanas e africanos e sua descendência em situação de escravidão.

No caso dos museus de Salvador, alguns desses objetos contam com muitos anos de musealização, tendo alcançado uma suposta estabilidade expositiva, na qual o seu modo de apresentar-se ao público conta, para além dos aspectos hegemônicos, com certa homogenia expositiva. Ao se pensar em descolonização do olhar os aspectos polissêmicos dos objetos precisam ser evidenciados, destacando os aspectos heterogêneos. Mas, a heterogeneidade desestabiliza, põe em xeque os conceitos consolidados, como argumenta Victorien Lavou Zoungbo:

O heterogêneo fascina e inquieta ao mesmo tempo. Inquieta mais do que fascina. [...] O heterogêneo, ou o que se considera como tal, tem, intrinsecamente, um poder de contestação, ou pelo menos, de questionamento das categorias estabelecidas [...] Cada vez mais se insiste na necessidade de ter um olhar novo sobre o heterogêneo e o múltiplo, fora de certas demandas de princípio que durante longo tempo foram consideradas verdades científicas indiscutíveis. (LAVOU ZOUNGBO, 2002, p. 78-79) $)^{10}$.

Este texto buscou oferecer um olhar heterogêneo e questionador para as categorias de objetos de arte decorativa, que se estabeleceram com bases em verdades, ditas indiscutíveis, que terminaram por silenciar, invisibilizar e legar um lugar de subalternidade às memórias dos seres humanos escravizados. As histórias de vida de mulheres e homens provenientes do continente africano, através do perverso tráfico

\footnotetext{
${ }^{10}$ Tradução livre do original: "Lo heterogéneo fascina e inquieta a la vez. Inquieta aún más de lo que fascina. [... ] Lo heterogéneo, o lo que se considera como tal, tiene, intrínsecamente, un poder de contestación, o por lo menos, de cuestionamiento de las categorías establecidas [...] Cada vez más se insiste en la necesidad de tener una mirada nueva sobre lo heterogéneo y lo múltiple, por fuera de ciertas peticiones de principio que durante largo tiempo fueron consideradas verdades científicas indiscutibles" (LAVOU ZOUNGBO, 2002, p. 78-79).
} 
negreiro, precisam ser recuperadas, estudadas, documentadas e expostas nos processos museais, nos quais as suas vidas estão implicadas.

As louças, os móveis, a prataria e os adornos de joias e demais elementos do mundo doméstico colonial e imperial estão marcados pelo suor, lágrimas e sangue de seres humanos escravizados; essa história precisa ser contada, como destaca o martinicano Édouard Glissant:

Os africanos, vítimas do tráfico para as Américas, transportaram consigo para além da Imensidão das Águas o rastro/resíduo de seus deuses, de seus costumes, de suas linguagens. Confrontados à implacável desordem do colono, eles conheceram essa genialidade, atada aos sofrimentos, de fertilizar esses rastros/resíduos [...] (GLISSANT, 2013, p. 71).

Essas pessoas foram, de fato, agentes construtores da história da nação, não devem mais ficar no lugar sacralizado de subalternidade, pois elas sustentaram economicamente o sistema colonial e imperial brasileiro. Assim, no campo específico dos museus de arte decorativa, será preciso promover ações museais e museológicas que respondam aos desafios de "[...] escutar as vozes dos sujeitos e das culturas que estiveram mudas e/ou esquecidas por muito tempo e que agora reclamam seus direitos de passar da mudez à polifonia." (FREITAS, 2013, p. 124). ${ }^{11}$

Os caminhos para que os museus de arte decorativa possam passar da "mudez à polifonia” podem parecer utópicos, mas não impossíveis de serem vivenciados, pois é urgente que esta categoria de museus saía da suposta neutralidade, que tem privilegiado os formatos hegemônicos, como foi analisado neste texto. Um percurso metodológico para vivências museais e museológicas que possa incluir memórias e histórias afrodiaspóricas, historicamente silenciadas, poderia ser o da "poética da Relação", como defende Glissant:

\footnotetext{
${ }^{11}$ Tradução livre do original: "[...] escuchar las voces de los sujetos y de las culturas que estuvieron mudas y/u olvidadas por mucho tiempo y que ahora reclaman sus derechos de pasar de la mudez a la polifonía." (FREITAS, 2013, p. 124).
} 
[...] a poética da relação não é uma poética do magna, do indiferenciado, do neutro. Para que haja relação é preciso que haja duas ou várias identidades ou entidades donas de si e que aceitem transformar-se ao permutar com o outro. (GLISSANT, 2013, p. 45-46).

Os movimentos sociais do século XX forçaram importantes câmbios relativos aos registros de histórias e memórias das heranças coloniais, mas ainda há um largo caminho a ser perseguido, principalmente para os museus de arte decorativa, que têm seus acervos ancorados em bases eurocêntricas que contribuem para a sedimentação de mentalidades coloniais e para a permanência do "racismo internalizado", salientado anteriormente por bell hooks (2019, p. 32). Para começar a descolonizar o olhar em arte decorativa não há um livro de receitas, são necessárias reflexões-ações-reflexões processuais, seguindo as ponderações de Grada Kilomba (2019, p. 53): “[...] não é somente uma imensa, mas também urgente tarefa descolonizar a ordem eurocêntrica do conhecimento." As reflexões aqui postas partem de quase duas décadas de experiência docente na área de arte decorativa, vivenciadas profundamente nesses museus. Essa experiência nos autoriza a dizer que será preciso empreender processos criativos e transgressores que questionem os padrões cristalizados, incorporando relatos biográficos dos diversos personagens envolvidos nos objetos. De uma história única será preciso escrever e expor histórias diversas. Como bem salienta Kilomba (2019, p. 11 e 12), trata-se da "[...] responsabilidade de criar novas configurações de poder e de conhecimento" numa "[...] sociedade que vive da negação, ou até mesmo na glorificação da história colonial [...]".

\section{Referências}

ALENCASTRO, Luiz Felipe de. O trato dos viventes: formação do Brasil no Atlântico Sul séculos XVI e XVII. São Paulo: Companhia das Letras, 2000.

ARAÚJO, Emanoel. Arte, adorno, design e tecnologia no tempo da escravidão. São Paulo: Museu Afro Brasil, 2013. Catálogo Exposição, Curador: Emanoel Araújo. 
CARNEIRO, Suely. Racismo, sexismo e desigualdade no Brasil. São Paulo: Selo Negro, 2011.

CRUZ, Eliana Alves. Água de Barrela. Rio de Janeiro: Malê, 2018.

DIDI-HUBERMAN, George. Diante da imagem. Trad. Paulo Neves. São Paulo: Editora 34, 2013.

FRAGA, Walter. Encruzilhadas da liberdade: histórias de escravos e libertos na Bahia (1870-1910). $2^{a}$ ed. Rio de Janeiro: Civilização Brasileira, 2014.

FREITAS, Joseania Miranda. Memorias afro-descendientes y la museística: algunas reflexiones. Revista Brasileira do Caribe, São Luis-MA. v. 14, n. 27, p. 117-137, jul./dez. 2013. Disponível em: http://www.redalyc.org/pdf/1591/159130118006.pdf. Acesso em: 30 jul. 2019.

GLISSANT, Édouard. Introdução a uma poética da diversidade. Trad. de Enilce do Carmo Albergaria Rocha. Juiz de Fora: Editora UFJR. $1^{\text {a }}$ reimpressão, 2013.

HOOKS, bell. Olhares negros: raça e representação. Trad. Stephanie Borges. São Paulo: Elefante, 2019.

KILOMBA, Grada. Memórias da plantação: episódios de racismo cotidiano. Trad. Jess Oliveira. Rio de Janeiro: Cobogó, 2019.

LAVOU ZOUNGBO, Victorien. "La desdicha genealógica": intento de objetivación de una trayectoria universitaria. Revista Colombiana de Sociología, Bogotá, v. 7, n. 1, p. 75-97, 2002. Disponível em: http://www.bdigital.unal.edu.co/16270/1/11151-26724-1-PB.pdf. Acesso em: 30 jul. 2019.

MBEMBE, Achille. Crítica da razão negra. $2^{\text {a }}$ ed. Trad. Sebastião Nascimento. São Paulo: n1 edições, 2018.

MIGNOLO, Walter D. Aiesthesis decolonial; Artículo de reflexión. CALLE 14: Revista de Investigación en el campo del arte, Bogotá, v. 4, n. 4, p. 10-25, mayo 2010. Disponível em: https://revistas.udistrital.edu.co/index.php/c14/article/view/1224/1634 Acesso em: 03 jun 2019.

MOLES, Abraham A. Teoria dos objetos. Trad. Luíza Lobo. Rio de Janeiro: Edições Tempo Brasileiro, 1981. 
NASCIMENTO, Rosana A. D. O objeto museal, sua historicidade, implicações na ação documental e na dimensão pedagógica do museuCadernos de Sociomuseologia, Lisboa, v. 3, n. 3, p. 7-29, 1994. Disponível em:

https://revistas.ulusofona.pt/index.php/cadernosociomuseologia/article/view/304 Acesso em: 30 jul. 2019.

NEPOMUCENO, Nirlene. Testemunhos de poéticas negras: de Chocolat e a Companhia Negra de Revistas no Rio de Janeiro (1926-1927). 2006. Dissertação (Mestrado em História Social) - Programa de Pós-Graduação em História Social da Pontifícia Universidade Católica de São Paulo - PUC-SP, São Paulo, 2006. Disponível em: http://bdtd.ibict.br/vufind/Record/PUC_SP-1_32998826e45410cd8abdf7fodb9c6of6/ Details. Acesso em: 26 ago. 2019.

PEZZODIPANE, Rosane Vieira. Pós-colonial: a ruptura com a história única. Simbiótica; razão e sensibilidades, Vitória: UFES, v. único, n. 3, 2013. Disponível em: http://periodicos.ufes.br/simbiotica/article/view/5494. Acesso: 30 jul. 2019.

PINHO, Wanderley. História de um engenho no Recôncavo. 2. ed., il. e acrescida de um apêndice. São Paulo: Ed. Nacional; Brasília: Fundação Nacional Pró-Memória, 1982.

QUIJANO. Aníbal. Colonialidade do poder, eurocentrismo e América Latina. In: LANDER, Edgardo. (org.). A colonialidade do saber: eurocentrismo e ciências sociais. Perspectivas latino-americanas. Buenos Aires: CLACSO - Consejo Latinoamericano de Ciencias Sociales, 2005. Disponível em: http://biblioteca.clacso.edu.ar/clacso/sur-

sur/20100624103322/12_Quijano.pdf. Acesso em: 30 jul. 2019.

QUIJANO, Aníbal. Colonialidade do poder e classificação social. In: SANTOS, Boaventura de Sousa; MENESES, Maria Paula (Org.). Epistemologias do sul. São Paulo: Cortez, 2010.

REIS, Lysie. A liberdade que veio do ofício. Salvador: EDUFBA, 2013. Disponível em: https://repositorio.ufba.br/ri/handle/ri/16806. Acesso em: 30 jul. 2019.

ROCHE, Daniel. História das coisas banais; nascimento do consumo séc. XVII-XIX. Trad. Ana Maria Scherer. Rio de Janeiro: Rocco, 2000.

ROSA, Mercedes. A prata da casa: um estudo sobre a ourivesaria no Museu Carlos Costa Pinto. Salvador: Conselho Federal de Cultura, 1980.

SANTOS, Boaventura de Sousa; MENESES, Maria Paula. (orgs.). Epistemologias do Sul. São Paulo: Cortez, 2010.

SPIX, Johann Baptist Von; MARTIUS, Carl Friedrich Philipe Von. Viagem pelo Brasil. 3. ed. São Paulo: Melhoramentos, 1976. 3 v. 
Recebido em: 18/09/2019

Aprovado em: 05/02/2020

Universidade do Estado de Santa Catarina - UDESC

Centro de Ciências Humanas e da Educação - FAED

Revista PerCursos

Volume 20 - Número 44 - Ano 2019 revistapercursos@gmail.com 